\title{
A RESISTÊNCIA SISTÊMICA INDUZIDA COMO ALTERNATIVA SUSTENTÁVEL AO USO DE AGROTÓXICOS
}

\author{
Liliane Roberta Mélo-Filho" \\ Mariana Guenther*
}

RESUMO: O uso de novas tecnologias de controle aos fitopatógenos que não ponham em risco a saúde humana e não agridam ao meio ambiente tem se tornado imprescindível como alternativa ao uso de substâncias tóxicas na agricultura. A resistência sistêmica induzida (RSI) consiste na ativação do sistema de defesa natural da planta a partir de substâncias específicas, promovendo um amplo espectro de proteção às diversas culturas de importância econômica sem gerar prejuízos aos seus consumidores e ao ambiente. Vários indutores de resistência, bióticos e abióticos, estabelecidos no mercado ou ainda em teste, têm sido avaliados para o controle dos patógenos que mais atingem as variedades cultivadas no Brasil. Estas substâncias representam uma opção sustentável promissora no controle dos fitopatógenos, garantindo a eficiência na produção e comercialização das culturas de uma forma mais ecologicamente correta, economicamente viável e socialmente justa.

PALAVRAS-CHAVE: Agricultura Sustentável; Fitopatógenos; Meio Ambiente; Resistência Sistêmica Induzida.

\section{INDUCED SYSTEMIC RESISTANCE AS A SUSTAINABLE ALTERNATIVE TO AGRICULTURAL PESTICIDES}

ABSTRACT: New control technologies against phytopathogens that would neither harm people nor damage the environment have become indispensable as alternatives to pesticides in agriculture. Induced Systemic Resistance (ISR) is the activation of the plant's natural defense system derived from specific compounds and which promote a wide protection spectrum to different cultures of economic relevance without any damage to consumers or the environment. Several biotic and abiotic ISRs already on the market or under analysis have been evaluated for the control of pathogens that attack vegetal varieties in Brazil. The compounds represent a

\footnotetext{
* Graduação em Ciências Biológicas pela Universidade Federal Rural de Pernambuco (UFRPE), Especialização em Perícia, Auditoria e Gestão Ambiental pela Universidade de Pernambuco (UPE)

** Docente Adjunta do Instituto de Ciências Biológicas da Universidade de Pernambuco (UPE), Docente do Curso de Pós Graduação em Perícia, Auditoria e Gestão Ambiental da UPE; E-mail: mariguenther@gmail.com
} 
promising sustainable option in the control of pathogens and guarantee efficiency in the production and commercialization of cultures in a more ecologically correct way, economically viable and socially just manner.

KEY WORDS: Sustainable Agriculture; Phytopathogens; Environment; Induced Systemic Resistance.

\section{INTRODUÇÃO}

Os fitopatógenos compreendem uma grande classe de organismos que infectam as mais diversas culturas de importância econômica. Dentre eles, destacamse os fungos, bactérias e vírus pelos grandes danos que acarretam, atingindo todas as etapas de produção agrícola, desde o cultivo até a pós-colheita de frutos e hortaliças.

As soluções para controlar a incidência de infecções pelos fitopatógenos incluem: o controle químico, através da utilização de pesticidas (os agrotóxicos); o uso de cultivares mais resistentes seja por melhoramento convencional ou modificação genética - os transgênicos; e a aplicação de métodos tradicionais de cultivo, como rotação de culturas e sistemas agroflorestais, a produção dita "orgânica".

O controle químico ainda é a opção mais comumente utilizada na agricultura. Essas substâncias apresentam amplo espectro de ação e, portanto, afetam não só os organismos "indesejáveis", como todos os consumidores destas culturas, especialmente aqueles diretamente envolvidos na sua aplicação na lavoura. Além de se acumularem nos alimentos, os pesticidas contaminam o solo e o lençol freático, afetando uma grande diversidade de espécies terrestres e aquáticas.

Muitos agrotóxicos usados em algumas culturas não possuem registros ou são proibidos no Brasil, conforme dados do relatório 2010 da Agência Nacional de Vigilância Sanitária (ANVISA), sobre o Programa de Análise de Resíduos de Agrotóxicos em Alimentos (BRASIL, 2011). No entanto a fiscalização na aquisição e utilização desses produtos ainda é muito precária. Ciente destes prejuízos, a população vem exigindo um maior controle de qualidade na produção agrícola, com intuito de garantir alimentos seguros para o consumo, com menor agressão ao meio ambiente. 
A solução reside, portanto, na busca por alternativas ao uso destes produtos químicos. Dentre as novas tecnologias existentes, a indução de resistência constitui uma opção eficaz e sustentável para a proteção das culturas aos patógenos, reduzindo tanto a probabilidade de infecção quanto a sua intensidade. Trata-se da ativação induzida do sistema de defesa natural da planta a partir de substâncias específicas (STASKAWICZ et al., 1995), promovendo um amplo espectro de proteção às diversas culturas de importância econômica sem gerar prejuízos ao meio ambiente, aos consumidores e às pessoas diretamente envolvidas na aplicação dos agrotóxicos.

\section{A RESISTÊNCIA SISTÊMICA INDUZIDA}

Na natureza, a grande maioria das interações entre plantas e microrganismos resulta em uma relação incompatível, ou seja, não há manifestação de doença. Para que esta ocorra, é necessária uma combinação de fatores propícios como: um patógeno altamente infeccioso, uma planta bastante suscetível e condições ambientais (temperatura e umidade) favoráveis (AGRIOS, 1997).

Em interações incompatíveis, são imediatamente ativados mecanismos de defesa da planta, resultando na expressão da hipersensibilidade (morte programada de células), produção de metabólitos secundários antimicrobianos (fitoalexinas), produção de proteínas de defesa relacionadas à patogênese e/ou lignificação dos tecidos, impedindo o estabelecimento do patógeno (STICHER et al., 1997).

A reação da planta a determinado patógeno pode ser determinada por herança genética ou induzida, onde esta passa a apresentar um estado geral de defesa após uma infecção inicial (MÉTRAUX, 2001). A resistência sistêmica induzida (RSI) pode ser acionada por uma série de substâncias, bióticas ou abióticas, que ativam o sistema de defesa da planta através de várias etapas e rotas, e são potencializadas após a interação com o patógeno (RYALS et al., 1996; KÚC, 2001).

\section{PRINCIPAIS INDUTORES DE RESISTÊNCIA A PATÓGENOS}

Dentre os vários compostos químicos (abióticos) com ação de ativador do sistema de defesa vegetal, sejam eles endógenos ou exógenos à planta, temos: 
Acibenzolar-S-metil (ASM), Ácido Salicílico (AS), Ácido Dicloroisonicotínico (INA), Probenazol (PBZ) e Metil-Jasmonato (MJ), este último um hormônio endógeno à planta (BARILLI et al., 2010; FURTADO et al., 2010; GÖRLACH et al., 1996).

Os indutores bióticos incluem: patógenos ativos ou inativados; linhagens não patogênicas como as leveduras da espécie Saccharomyces cerevisiae; metabólitos microbianos como o Harpin, proteína sintetizada por bactérias da espécie Erwinia amylovora; extratos de plantas (Reynoutria sachalinensis); de algas (Ulva sp.; Laminaria digitata); e de animais, como a quitosana, derivada dos crustáceos (DONG et al., 1999; ABREU et al., 2008; BERGER et al., 2011).

As crescentes pesquisas envolvendo indução de resistência em plantas vêm proporcionando o surgimento de novos produtos no mercado que já apresentam comprovada eficácia, estabilidade e menor impacto ao ambiente do que os agrotóxicos, e, em alguns casos, até proporcionam incrementos no desenvolvimento vegetativo. Dentre as substâncias já amplamente comercializadas temos: Oryzemate ${ }^{\circledR}$ (Probenazol), Bion ${ }^{\circledR}$ (Acibenzolar-S-metil), Messenger ${ }^{\circledast}$ (Harpin), Elexa ${ }^{\circledR}$ (quitosana), Agro-mós $^{\circledR}$ (derivado da parede celular de Saccharomyces cerevisiae), Milsana ${ }^{\circledR}$ (extrato de Reynoutria sachalinesis), Ecolife ${ }^{\circledast}$ (biomassa cítrica), Iodus ${ }^{\circledR}$ (extrato de Laminaria digitata) (RIBEIRO JUNIOR; RESENDE, 2012).

\section{A UTILIZAÇÃO DE INDUTORES DE RESISTÊNCIA NO CONTROLE DE FITOPATÓGENOS}

De um modo geral os testes desenvolvidos com cultivares brasileiras têm demonstrado resultados bastante promissores tanto com indutores bióticos e abióticos disponíveis no mercado, quanto com novos extratos naturais. A grande maioria se mostrou altamente eficiente no controle ou na diminuição da severidade das doenças nos patossistemas estudados (Quadro 1). 
Quadro 1. Indutores de resistência bióticos e abióticos utilizados no controle de patógenos (fungos e bactérias) de algumas culturas brasileiras

\begin{tabular}{|c|c|c|c|}
\hline Indutor & Cultura & Patógeno & Referência \\
\hline ASM & Maracujá & $\begin{array}{l}\text { Mancha bacteriana (Xanthomonas } \\
\text { axonopodis pv. passiflorae) }\end{array}$ & BORO et al., 2011 \\
\hline ASM e BABA & Ervilha & Ferrugem (Uromyces pisi) & BARILLI et al., 2010 \\
\hline Agro-Mos ${ }^{\circledR}$ & Cacau & $\begin{array}{l}\text { Vassoura-de-bruxa (Moniliophthora } \\
\text { perniciosa) }\end{array}$ & COSTA et al., 2010 \\
\hline Ecolife $^{\circledR}$ & Abacaxi & Podridão-negra (Chalaria paradoxa) & $\begin{array}{l}\text { OLIVEIRA; } \\
\text { NASCIMENTO, } 2009\end{array}$ \\
\hline ASM e Ecolife ${ }^{\circledR}$ & Banana & Antracnose (Colletotrichum musae) & FURTADO et al., 2010 \\
\hline $\begin{array}{l}\text { Extrato de } \\
\text { manjericão }\end{array}$ & Pepino & $\begin{array}{l}\text { Antracnose (Colletotrichum } \\
\text { lagenarium) }\end{array}$ & COLPAS et.al., 2009 \\
\hline $\begin{array}{l}\text { Extrato de } \\
\text { Ulva sp. }\end{array}$ & Feijão & Ferrugem (Uromyces appendiculatus) & DELGADO et al., 2013 \\
\hline $\begin{array}{l}\text { Extrato de } \\
\text { Ulva sp. }\end{array}$ & Maçã & $\begin{array}{l}\text { Mancha foliar da gala (Colletotrichum } \\
\text { gloeosporioides) }\end{array}$ & ARAÚJO et al., 2008 \\
\hline $\begin{array}{l}\text { Extrato de } \\
\text { cogumelos }\end{array}$ & Tomate & $\begin{array}{l}\text { Mancha bacteriana (Xanthomonas } \\
\text { vesicatoria) }\end{array}$ & DI PIERO, 2004a \\
\hline $\begin{array}{l}\text { Extrato de } \\
\text { cogumelos }\end{array}$ & Pepino & $\begin{array}{l}\text { Antracnose (Colletotrichum } \\
\text { lagenarium) }\end{array}$ & DI PIERO, 2004b \\
\hline $\begin{array}{l}\text { Extratos de } \\
\text { Rhodophyta* }\end{array}$ & Mamoeiro & $\begin{array}{l}\text { Antracnose (Colletotrichum } \\
\text { gloeosporioides) }\end{array}$ & $\begin{array}{l}\text { MACHADO et al., } \\
2011\end{array}$ \\
\hline
\end{tabular}

* potencial utilização como indutores de resistência

\subsection{INDUTORES ABIÓTICOS COMERCIALIZADOS}

Dentre os indutores abióticos, o acibenzolar-S-metil (ASM) é o mais comumente utilizado e único registrado no Brasil como indutor de resistência para as culturas de algodão, batata, cacau, citros, feijão, melão e tomate (RIBEIRO JUNIOR; RESENDE, 2012). Os trabalhos desenvolvidos demonstraram uma alta eficiência do ASM no controle e manejo de doenças causadas tanto por bactérias quanto por fungos.

Quando testado para o controle da "mancha bacteriana" (Xanthomonas axonopodis pv. passiflorae) em plantas de maracujá, o ASM conferiu proteção de até $70 \%$ dos indivíduos estudados na concentração de 12,5 $\mu \mathrm{g} \mathrm{mL}^{-1}$ (BORO et al., 2011). 
Também se mostrou eficaz no controle da "ferrugem" (Uromyces pisi) em plantas de ervilha, juntamente com o ácido $\beta$-aminobutírico (BABA), nas concentrações de 10mM e 5mM, respectivamente (BARILLI et al., 2010).

\subsection{INDUTORES BIÓTICOS COMERCIALIZADOS}

Dos indutores bióticos, os mais amplamente utilizados nas pesquisas com cultivares no Brasil são: Agro-Mos ${ }^{\circledR}$ - mananoligossacarídeo fosforilado proveniente da parede celular de Saccharomyces cerevisiae, e Ecolife ${ }^{\circledR}$ - "biomassa cítrica": mistura de bioflavanóides, fitoalexinas, polifenóis, glicerina vegetal, ácidos ascórbico, lático e cítrico (RIBEIRO JUNIOR; RESENDE, 2012). Quando comparados aos indutores abióticos, esses têm se mostrado mais eficazes na indução de resistência de algumas plantas testadas.

Estudos sobre a indução de resistência à infecção pelo fungo Moniliophthora perniciosa - "a vassoura de bruxa" em plantas de cacaueiro, não demonstraram efeito protetor do ASM nas concentrações utilizadas: $0.1 \mathrm{~g} \mathrm{~L}^{-1}, 0.2 \mathrm{~g} \mathrm{~L}^{-1} \mathrm{e} 1.0 \mathrm{~g} / \mathrm{L}^{-1}$, enquanto que o Agro-Mos ${ }^{\circledR}$ se mostrou eficiente nas dosagens de $10.0 \mathrm{~mL} \mathrm{~L}^{-1}, 5.0 \mathrm{~mL}$ $\mathrm{L}^{-1}$ e $2.5 \mathrm{~mL} \mathrm{~L}^{-1}$ (COSTA et al., 2010).

O controle pós-colheita da "podridão-negra" (Chalaria paradoxa) em frutos de abacaxi pérola também foi mais eficaz com o uso do Ecolife ${ }^{\circledR}$, na concentração 1,0 $\mathrm{mL} \mathrm{L}^{-1}$, do que em relação ao ASM (OLIVEIRA; NASCIMENTO, 2009).

Já o controle pós-colheita da atracnose em frutos de bananas provenientes de diferentes variedades (maçã, prata, pacovan e cacau) se mostrou igualmente eficaz com o Ecolife ${ }^{\circledR}$ na concentração de $5 \mathrm{~mL} \mathrm{~L}^{-1} \mathrm{e}$ com o ASM na concentração de $0,5 \mathrm{~g} \mathrm{~L}^{-1}$ (FURTADO et al., 2010).

\subsection{POTENCIAL DE UTILIZAÇÃO DE OUTROS EXTRATOS DE PLANTAS, ALGAS E FUNGOS}

Muitos estudos vêm demonstrando a indução de resistência a partir de outros extratos e bioativos de plantas, algas e fungos, apontando para uma maior diversificação destas substâncias a serem futuramente lançadas no mercado. 
Extratos de manjericão cravo (Ocimum gratissimum) nas concentrações de 10, 25, 40 e 50\% (p/v), induziram resistência em plantas de pepino no controle da antracnose (Colletotrichum lagenarium), reduzindo a incidência da doença quando tratadas três dias antes da inoculação do patógeno (COLPAS et al., 2009).

A ulvana, polissacarídeo derivado das algas verdes do gênero Ulva (Chlorophyta), quando usada na concentração de $10 \mathrm{mg} \mathrm{mL}^{-1}$, resultou na indução de resistência à ferrugem (Uromyces appendiculatus) em plantas de feijão (Phaseolus vulgaris), quando tratadas três dias antes da inoculação do patógeno (DELGADO et al., 2013).

A mesma substância se mostrou eficaz também no controle da mancha foliar da gala (Colletotrichum gloeosporioides) em macieiras, na mesma concentração e período de inoculação (ARAUJO et al., 2008). O mesmo estudo demonstrou que o uso da ulvana no período de apenas três dias antes da inoculação do patógeno não apresentou efeito significativo, devido à necessidade de um intervalo maior de tempo para que a planta iniciasse a sequência de eventos relacionados à ativação de sinais sistêmicos de defesa em órgãos não tratados. Esses dados mostram que a dosagem e o tempo de aplicação dos indutores devem ser observados para cada patossistema específico, pois estes podem ser variáveis.

Extratos de cogumelos como o shiitake (Lentinula edodes) e o cogumelodo-sol (Agaricus blazei) também induziram a resistência de plantas de pepino no controle da antracnose (Colletotrichum lagenarium), e do tomateiro no controle da mancha bacteriana - Xanthomonas vesicatoria (DI PIERO; PASCHOLATI, 2004a; 2004b; DI PIERO et al., 2006).

Extratos de espécies de algas vermelhas (Rhodophyta), como Laurencia dendroidea e Ochtodes secundiranea, apresentaram grande potencial de inibição de crescimento do fungo Colletotrichum gloesporioides, proveniente de lavouras de mamoeiros (MACHADO et al., 2011). Ainda não foram testados como indutores de resistência, mas a grande diversidade deste grupo na flora litorânea brasileira representa mais um grande potencial de substâncias a serem exploradas para 0 controle de fitopatógenos de forma sustentável. 


\section{CONSIDERAÇÕES FINAIS}

O uso de indutores de resistência nas variedades cultivadas em solo brasileiro representa uma alternativa promissora no controle dos fitopatógenos, garantindo a eficiência na produção e comercialização destas culturas e evitando a utilização de agrotóxicos.

Muitos estudos ainda são necessários no sentido de se adequar a dosagem de aplicação do indutor, o estágio de desenvolvimento da planta e o período pósinfecção para cada patógeno específico nas diferentes variedades de cultivares. No entanto, as vantagens do uso de indutores de resistência em relação aos agrotóxicos comumente utilizados são, de fato, incontestáveis.

Do ponto de vista da eficiência no controle dos patógenos, os pesticidas clássicos tendem a diminuir seu efeito com o tempo de exposição, uma vez que os patógenos vão adquirindo resistência através da seleção natural. Além disso, os pesticidas possuem um espectro mais restrito de ação, sendo pouco eficazes, por exemplo, para os patógenos de solo. A resistência sistêmica induzida, ao contrário, apresenta um amplo espectro de ação por ser ativada a partir da infecção específica. Além disso, uma vez que vários mecanismos de defesa são ativados, o desenvolvimento de resistência dos patógenos é menos provável, sendo então efetiva por muito mais tempo.

Do ponto de vista social e da saúde do homem, a utilização da RSI evita a contaminação dos alimentos com produtos tóxicos e elimina os perigos associados à aplicação dos pesticidas aos trabalhadores desse setor. Além disso, na RSI não há a introdução de genes nas plantas como ocorre nos organismos transgênicos - o que gera ainda uma grande desconfiança e resistência por parte da população. Os genes ativados no processo de indução de resistência são próprios da planta.

Do ponto de vista ambiental, não há geração de resíduos, uma vez que os indutores de resistência são inoculados diretamente na planta. Além disso, essas substâncias são provenientes de extratos ou metabólitos naturais, sendo, portanto, atóxicos para o ambiente.

Do ponto de vista econômico, os indutores de resistência representam uma alternativa mais viável em relação aos agrotóxicos; são facilmente encontrados 
na natureza por tratarem-se de substâncias já presentes nos organismos, o que diminuiria seu custo de produção em larga escala. Além disso, os crescentes estudos que revelam os efeitos nocivos dos agrotóxicos vêm auxiliando a fiscalização das agências reguladoras de modo que muitos pesticidas são sistematicamente removidos do mercado e substituídos por outros. Essa substituição acarreta um grande custo, principalmente ao pequeno produtor.

Sendo assim, a resistência sistêmica induzida vem pouco a pouco se firmando como uma alternativa sustentável na agricultura: ecologicamente correta, economicamente viável e socialmente justa.

\section{REFERÊNCIAS}

ABREU, G. F.; TALAMINI, V.; STADNIK, M. J. Bioprospecção de macroalgas marinhas e plantas aquáticas para o controle da antracnose do feijoeiro. Summa Phytopathologica, Botucatu, v. 34, n. 1, p. 78-82, 2008.

AGRIOS, G. N. Plant Pathology. San Diego, Academic Press, 1997.

ARAÚJO, L.; STADNIK, M. J.; BORSATO, L. C.; VALDEBENITE-SANHUREZA, R. M. Fosfito de potássio e ulvana no controle da mancha foliar da gala em macieira. Tropical Plant Pathology, Brasília, v. 33, n. 2, p. 148-154, 2008.

BARILLI, E.; SILLERO, J. C.; RUBIALES, D. Systemic acquired resistance in pea against rust (Uromyces pisi) by exogenous application of biotic and abiotic inducers. Journal of Phytopathology, Berlim, v. 158, p. 30-34, 2010.

BERGER, L. R. R.; STAMFORD, T. C. M.; STAMFORD, N. P. Perspectivas para o uso da quitosana na agricultura. Revista Iberoamericana de Polímeros, v. 12, n. 4, p. 195-215, 2011.

BORO, M. C.; BERIAM, L. O. S.; GUZZO, S. D. Induced resistance against Xanthomonas axonopodis pv. passiflorae in passion fruit plants. Tropical Plant Pathology, Brasília, v. 36, n. 2, p. 74-80, 2011. 
BRASIL, 2011. ANVISA - Programa de Análise de Resíduos de Agrotóxicos em Alimentos (PARA) - Relatório de atividades 2010. 26p. Disponível em: http://portal. anvisa.gov.br

COLPAS, F. T.; SCHWAN-ESTRADA, K. R. F.; STANGARLIN, J. R.; FERRARESE, M. L.; SCAPIM, C. A.; BONALDO, S. M. Induction of plant defense responses by Ocimum gratissimum L. (Lamiaceae) leaf extracts. Summa Phytopathologica, Botucatu, v. 35, n. 3, p. 191-195, 2009.

COSTA, J. C. B.; RESENDE, M. L. V.; RIBEIRO JÚNIOR, P. M.; CAMILO, F. R.; MONTEIRO, A. C. A.; PEREIRA, R. B. Indução de resistência em mudas de cacaueiro contra Moniliophthora perniciosa por produto à base de mananoligossacarídeo fosforilado. Tropical Plant Pathology, Brasília, v. 35, n. 5, p. 285-294, 2010.

DELGADO, D. Z.; FREITAS, M. B.; STADNIK, M. J. Effectiveness of saccharin and ulvan as resistance inducers against rust and angular leaf spot in bean plants (Phaseolus vulgaris). Crop Protection, Guilford, v. 47, p. 67-73, 2013.

DI PIERO, R. M.; PASCHOLATI, S. F. Efeito dos cogumelos Lentinula edodes e Agaricus blazei na interação entre plantas de tomate e Xanthomonas vesicatoria. Summa Phytopathologica, Botucatu, v. 30, n. 1, p. 57-62, $2004 a$.

DI PIERO, R. M.; PASCHOLATI, S. F. Indução de resistência em plantas de pepino contra Colletotrichum lagenarium pela aplicação de extratos de basidiocarpos de Lentinula edodes e de Agaricus blazei. Summa Phytopathologica, Botucatu, v. 30, n. 2, p. 243-250, 2004b.

DI PIERO, R. M.; WULFF, N. A.; PASCHOLATI, S. F. Partial purification of elicitors from Lentinula edodes basidiocarps protecting cucumber seedlings against Colletotrichum lagenarium. Brazilian Journal of Microbiology, v. 37, n. 2, p. 175-180, 2006.

DONG, H.; DELANEY, T. P.; BAUER, D. W.; BEER, S. V. Harpin induces disease resistance in Arabidopsis through the systemic acquired resistance pathway mediated by salicylic acid and the NIM1 gene. The Plant Journal, v. 20, n. 2, p. 207-215, 1999. 
FURTADO, L. M.; RODRIGUES, A. A. C.; ARAÚJO, V. S.; SILVA, L. L. S.; CATARINO, A. M. Utilização de Ecolife ${ }^{\circledR}$ e Acibenzolar-s-metil (ASM) no Controle da Antracnose da banana em pós-colheita. Summa Phytopathologica, Botucatu, v. 36, n. 3, p. 237-239, 2010.

GÖRLACH, J.; VOLRATH, S.; KNAUF-BEITER, G.; HENGY, G.; BECKHOUE, U.; KOGEL, K. H.; OOSTENDORF, M.; STAUB, T.; WARD, E.; KESMANN, H.; RYALS, J. Benzothiadiazole, a novel class of systemic acquired resistance, activate genes expression and disease resistance in wheat. The Plant Cell, Rockville, v. 8, p. 629$643,1996$.

KÚC, J. Concepts and direction of induced systemic resistance in plants and its application. European Journal of Plant Pathology, Dordrecht, v. 107, p. 7-12, 2001.

MACHADO, L. P.; BISPO, W. M. S.; MATSUMOTO, S. T.; REIS, F. O.; SANTOS, R. B.; OLIVEIRA JUNIOR, L. F. G. Triagem de macroalgas com potencial antifúngico no controle in vitro da antracnose do mamoeiro (Carica papaya 1.). Revista Brasileira de Agrociências, Pelotas, v. 17, n. 4, p. 463-467, 2011.

MÉTRAUX, J. P. Systemic acquired resistance and salicylic acid: current state of knowledge. European Journal of Plant Pathology, Dordrecht, v. 107, p. 13-18, 2001.

OLIVEIRA, M. D. M.; NASCIMENTO, L. C. Avaliação da atividade de indutores de resistência abiótica, fungicida químico e extratos vegetais no controle da podridão negra em abacaxi 'pérola'. Revista Brasileira de Fruticultura, Jaboticabal, v. 31, n. 1, p. 84-89, 2009.

RIBEIRO JUNIOR, P. M.; RESENDE, M. L. V. Indutores disponíveis comercialmente. Workshop Insumos para Agricultura Sustentável, Embrapa Clima Temperado, Pelotas, 2012.

RYALS, J. A.; NEUENSCHWANDER, V. H.; WILLITS, M. G.; MOLINA, A.; STEINER, H. V.; HUNTER, M. D. Systemic acquired resistance. The Plant Cell, Rockville, v. 8, p. 1809-1819, 1996. 
STASKAWICZ, B. J.; AUSUBEL, F. M.; BAKER, B. J.; ELLIS, J. G.; JONES, J. D. G. Molecular genetics of plant disease resistance. Science, Washington, v. 268, p. 661667, 1995.

STICHER, L.; MANI, B. M.; MÉTRAUX, J. P. Systemic acquired resistance. Annual Review Phytopathology, Palo Alto, v. 35, p. 235-270, 1997.

Recebido em: 27 de setembro de 2013 Aceito em: 09 de junbo de 2014 